\title{
Coronavirus disease-2019: Infection control and prevention measures in dental radiology
}

\author{
(1) Vijayendranath Nayak', (1) Ujwala Shetty ${ }^{2}$, (1) Prasanna Kumar Rao², (1) Raghavendra Kini²
}

${ }^{1}$ Manipal University College Malaysia, Faculty of Dentistry, Department of Oral Medicine and Oral Radiology, Melaka, Malaysia

${ }^{2}$ A. J. Institute of Dental Sciences, Department of Oral Medicine and Radiology, Karnataka, India

Date submitted:

22.01.2021

Date accepted:

22.04.2021

Online publication date:

15.03.2022

\section{Corresponding Author:}

Vijayendranath Nayak, M.D.S, Manipal University College Malaysia, Faculty of Dentistry, Department of Oral Medicine and Oral Radiology, Melaka, Malaysia drnayakomr@gmail.com

\section{ORCID:}

orcid.org/0000-0003-0991-8355

Keywords: COVID-19, radiology, radiology dentistry, cone-beam computed tomography, pandemics

\section{Dear Editor,}

A public health emergency of international concern (PHEIC) was declared over Coronavirus disease-2019 (COVID-19), which is the sixth time World Health Organization (WHO) has declared a PHEIC since the International Health Regulations took effect in 2005 (1). Hegde and Ajila (2), described the situation of Indian dentists during the pandemic, however, adding a note on infection control protocol is of highest importance. Dentists were unaware of which guidelines to follow. The dental clinics were advised to remain closed in the containment zone and to continue with teledentistry. A survey found that only $40 \%$ of radiology department professional staff have enough knowledge of infection control practice (3). The Centers for Disease Control and Prevention have recommended that the dental healthcare personnel (DHCP) should be provided with education and training to prevent transmission of infectious agents, including refresher training. The main goal is safe care for the community through educating and training the DHCP to properly use the protective equipment before approaching a patient. In the absence of specific drugs, the protective measures in the dental radiology departments primarily target controlling the transmission routes such as droplets, contact surfaces, and aerosols (4).

Healthcare workers, including medical and dental radiologists, have been the frontline in the COVID-19 pandemic, hence, reinforcement of infection control protocols becomes crucial. The oral radiologists and technicians must use the personnel protective equipment, including eye protection, a filtering facepiece respirator (N95), a surgical cap, gloves, a fluid-resistant gown, and shoe cover (5).

Severe acute respiratory syndrome Coronavirus-2 (SARS-CoV-2) virus has been identified in both blood and saliva samples of COVID-19 patients, which necessitates reviewing our current practice to prevent infections. Hand hygiene is the most critical measure to reduce the risk of transmitting microorganisms between individuals. SARSCoV-2 can persist on surfaces from a few hours or to several days, depending on the type of surface, temperature, or humidity of the environment. Thus, the need for hand hygiene and thorough disinfection of all surfaces within the radiology department is of high priority (6). 
The use of autoclaved or disposable film/receptor holders is recommended to reduce the clinician's contact with saliva while placing the film/receptor. Switching off the X-ray unit before cleaning and disinfection, remembering to wear protective gloves before touching the surfaces, and cleaning the surface using approved cleaning agents and surface disinfectants are essential. Disinfectants can be used in the form of wipes, and $0.5 \%$ hydrogen peroxide wipes can be used like Optim Blue wipes (7). The client green, a boxed wipe is designed for universal cleaning and is a licensed cleaning agent for medical equipment. It contains $2 \%$ chlorhexidine and $70 \%$ ethanolbased alcohol (8). The use of gloves for touching the radiology unit is also mandatory.

Radiology departments should contact their equipment vendors to find the safest disinfectant for each piece of equipment in use (9). The use of sprays, liquids, or foams directly on any surface of the extraoral unit is not suggested by most equipment providers. The use of clean, damp cloth is preferred by most manufacturers (10). According to Spaulding's Classification of Medical Equipment/Devices, surfaces of a radiology unit need to be either washed with soap and water or decontaminated using low-level or intermediate-level disinfectants, such as iodophor germicidal detergent solution, ethyl alcohol, or isopropyl alcohol (10). Changing the bite stick for each patient or using a disposable protective shield should be preferred. Wiping all the parts after exposure of each patient, by using surface disinfectant approved by the equipment provider should not be avoided. Some parts can be autoclaved at $134^{\circ} \mathrm{C}\left(273^{\circ} \mathrm{F}\right)$ : A 3-4-minute cycle.

Cone-beam computed tomography (CBCT) units can be disinfected using the above modes of disinfection; however, other parts of CBCT units that are non-critical like a remote switch, control panel, chin rest, handgrips, head stabilizers, patient table, and patient chair should be handled as described above, and disposable bite guides must be used if barrierprotection or sterilization is not possible.

In conclusion, the DHCP must provide the best available standards of safe operating procedures for their patients and themselves.

\section{Ethics}

Peer-review: Externally peer-reviewed.

\section{Authorship Contributions}

Surgical and Medical Practices: V.N., U.S., Concept: V.N., P.K.R., Design: V.N., R.K., Data Collection or Processing: V.N.,
U.S., Analysis or Interpretation: R.K., P.K.R., Literature Search: U.S., R.K., Writing: P.K.R., V.N.

Conflict of Interest: No conflict of interest was declared by the authors.

Financial Disclosure: The authors declared that this study received no financial support.

\section{References}

1. Zhu N, Zhang D, Wang W, et al. A novel coronavirus from patients with pneumonia in China, 2019. N Engl J Med. 2020;382:727-733

2. Hegde S, Ajila V. COVID-19 pandemic and dental health care system: An Indian scenario. Gulhane Med J. 2020;62:284-285.

3. Peng J, Ren N, Wang M, Zhang G. Practical experiences and suggestions on the eagle-eyed observer, a novel promising role for controlling nosocomial infection of the COVID-19 outbreak. J Hosp Infect. 2020;105:106-107.

4. Zhonghua Liu, Xing Bing, Za Zhi. The epidemiological characteristics of an outbreak of 2019 novel coronavirus diseases (COVID-19) in China. Chinese Journal of Surgery 2020; 41:145-151. Available from: https://pubmed.ncbi.nIm. nih.gov/32064853/

5. Nakajima K, Kato H, Yamashiro T, et al. COVID-19 pneumonia: infection control protocol inside computed tomography suites. Jpn J Radiol. 2020;38:391-393.

6. Meng L, Hua F, Bian Z. Coronavirus Disease 2019 (COVID-19): Emerging and Future Challenges for Dental and Oral Medicine. Journal of Dental Research. 2020;99:481-487.

7. Cadnum JL, Mana TS, Jencson A, Thota P, Kundrapu S, Donskey CJ. Effectiveness of a hydrogen peroxide spray for decontamination of soft surfaces in hospitals. Am J Infect Control. 2015;43:1357-1359.

8. Kyratsis $\mathrm{Y}$, Ahmad R, Hatzaras K, Iwami M, Holmes A. Making sense of evidence in management decisions: the role of research-based knowledge on innovation adoption and implementation in health care. Southampton (UK): NIHR Journals Library; 2014:6. Available from: https://pubmed.ncbi. nlm.nih.gov/25642560/

9. Kooraki S, Hosseiny M, Myers L, Gholamrezanezhad A. Coronavirus (COVID-19) outbreak: what the department of radiology should know. J Am Coll Radiol. J Am Coll Radiol. 2020;17:447-451.

10. Mirza SK, Tragon TR, Fukui MB, Hartman MS, Hartman AL. Microbiology for radiologists: how to minimize infection transmission in the radiology department. Radiographics. 2015;35:1231-1244. 